\title{
Dilated Cardiomyopathy in Behcet's Disease in a Young Male Patient
}

\author{
Hamid Khederlou ${ }^{1,}$, Samin Taheri ${ }^{1}$, Alireza Sadeghi ${ }^{2}$, \\ Amirhossein Moghtader Mojdehi ${ }^{3}$
}

\author{
${ }^{1}$ School of Medicine, Student Research Center, Zanjan University of Medical \\ Sciences, Zanjan, Iran \\ ${ }^{2}$ Assistant Professor, Department of Rheumatology, Zanjan University of Medical \\ Sciences, Zanjan, Iran \\ ${ }^{3}$ Assistant Professor, Department of Infectious Disease, Zanjan University of Medi- \\ cal Science, Zanjan, Iran \\ * Corresponding author: Hamid Khederlou, School of Medicine, Student Research \\ Center, Zanjan University of Medical Sciences, Zanjan, Iran.E-mail: ham_khed@ \\ yahoo.com
}

DOI: $10.21859 /$ ijcp-030102

\begin{tabular}{l} 
Submited: 06-17-2017 \\
Accepted: 08-02-2017 \\
\hline
\end{tabular}

Keywords:

Behcet Syndrome

Cardiomyopathies

(C) 2017. International Journal of

Cardiovascular Practice.

\begin{abstract}
Behcet's disease is a multi-systemic, inflammatory, and chronic disorder characterized by recurrent oral aphthous ulcers, genital ulcers, uveitis, and other systemic organ involvement. Cardiac involvement in Behcet's disease is rare; however, it plays an important role in prognosis and increases mortality. The current researchers hereby have reported a case of Behcet's disease with dilated cardiomyopathy. A 28-year-old male patient was presented with constitutional symptoms, oral and genital aphthous ulcers, pseudofolliculitis, tachycardia, arthritis, splenomegaly, erythrocyte sedimentation rate and C-reactive protein elevation, and left ventricular systolic dysfunction with left ventricular ejection fraction of $45 \%$. Azathioprine and prednisolone were begun for the patient.
\end{abstract}

\section{INTRODUCTION}

Behcet's disease (BD) is a multi-systemic, inflammatory, and chronic disorder characterized by a triple-symptom complex of recurrent oral aphthous ulcers, genital ulcers, uveitis $[1,2]$, and other diverse spectrum of clinical manifestations, including skin, joint, Central Nervous System (CNS), gastrointestinal, pulmonary, and cardiovascular system involvement, which are reported in addition to the major findings of this disorder. Cardiac involvement in $\mathrm{BD}$ is known as cardio-Behcet's disease that occurs in $7 \%$ to $31 \%$ of patients with BD, with a mortality rate of $20 \%$ [3]. Cardiac manifestations in $\mathrm{BD}$ include endocarditis, myocarditis, pericarditis, intracardiac thrombus, endomyocardial fibrosis, coronary arterial disease, cardiomyopathy, myocardial infarction, valvular disease, diastolic dysfunction, ventricular arrhythmias, and sudden cardiac death [4]. Cardiovascular involvement is rare, yet life-threatening, and early diagnosis has important therapeutic implications $[5,6]$. Sporadic cases of cardiovascular involvement like Cardiomyopathy (CM) have been reported. Degenerative changes and lysis of myocytes with cytoplasmic vacuolization, interstitial focal fibrinoid deposition, and fibroblast proliferation could be seen in CM due to BD [7, 8]. Although sub-endocardial longitudinal fibers will be the first affected region in patients with $\mathrm{BD}, \mathrm{BD}$ could effect any of the 3 layers of the heart or all of them at the same time [9]. Furthermore, CM in $\mathrm{BD}$ could be ischemic, non-ischemic, or inflammatory. It could manifest as systolic or diastolic heart failure, or even as asymptomatic systolic or diastolic dysfunction [10]. The clinical presentation of CM in BD could include fever, dyspnea, chest pain, hemoptysis, and edema [11]. The aim of this study was to report dilated cardiomyopathy in Behcet's disease in a young male patient.

\section{CASE PRESENTATION}

\section{General Description}

A 28-year-old male patient was admitted with fever, night sweats, anorexia, weight loss, pain, and swelling in the left knee. On examination, his body temperature, heart rate, and blood pressure were $38.4^{\circ} \mathrm{C}, 154 \mathrm{bit} / \mathrm{Min}$, and 96/63 $\mathrm{mmHg}$, respectively. The chest, heart, and abdomen examinations showed no abnormal findings. He had no lymphadenopathy. His left knee was tender and swollen. His clinical examination did not reveal any evidence of extraintestinal manifestation of inflammatory bowel disease. He had smoked 2 packs of cigarettes/day for 4 years. According to these presentations, the patient was worked up for Fever of Unknown Origin (FUO).On the third day of hospitalization, oral aphthous ulcers and pseudofolliculitis in the anterior of the thigh were found. The next day, genital ulcers 
appeared on the scrotum (Fig la, b, c). The patient reported recurrent oral and genital ulcers for the previous months. According to new findings on examination, rheumatologic consult was asked for the patient. Imaging and laboratory investigations results were as follows.

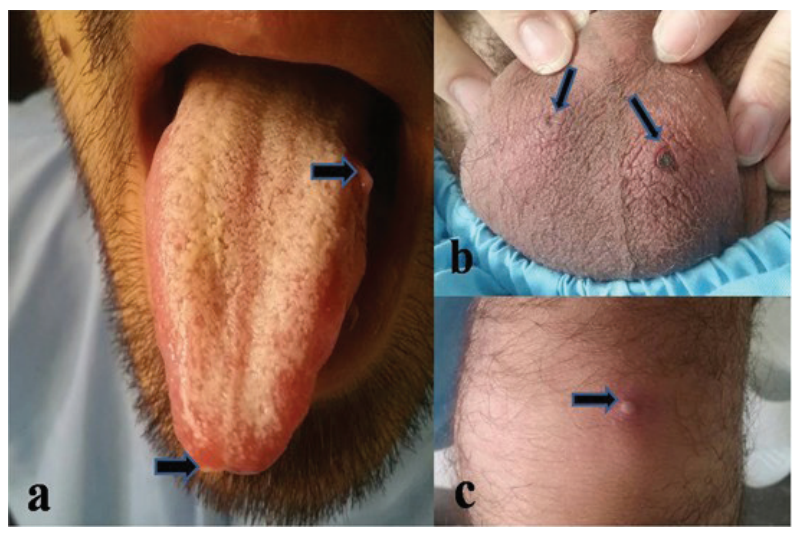

Figure 1: Oral Aphthous Ulcers (a), Genital Ulcers on the Scrotum (b) and Pseudofolliculitis in the Anterior of Thigh (c) were found on Examination.

\section{Laboratory Investigations}

The initial Complete Blood Count (CBC) revealed a hemoglobin count of $11.8 \mathrm{~g} / \mathrm{dL}$, a platelet count of $308 \times 10^{3} /$ $\mu \mathrm{L}$, and a white cell count of $11.4 \times 10^{3} / \mu \mathrm{L}$. The Erythrocyte Sedimentation Rate (ESR) and C - reactive protein (CRP) were elevated to $63 \mathrm{~mm} / \mathrm{hr}$ and $126 \mathrm{mg} / \mathrm{l}$, respectively. Coagulation screening tests, coagulation factors, and anticoagulation levels were within the normal range. Complement components, levels of IgA, IgG, and IgM were also normal. The results of his autoimmune screening tests, including perinuclear-Anti-Neutrophil Cytoplasmic Antibodies (p-ANCA), cytoplasmic-Anti-Neutrophil Cytoplasmic Antibodies (c-ANCA), Human Leukocyte Antigen-B27 (HLA-B27), Fluorescent Antinuclear Antibody (FANA), Antinuclear Antibody (ANA), anti ds_DNA and anti-Citrullinated Peptide Antibodies (Anti-CCP) were negative. His HLA-B51 was negative. The anticardiolipin antibodies, antiphospholipid antibodies, and lupus anticoagulant were negative. Brucellosis tests and Tuberculin Skin Test (TST) were negative. His serum troponin level was within the normal range. It is important to note that his pathergy test result was also negative. Analysis of left knee arthrocentesis showed inflammation. Blood culture $(\times 2)$ showed no growth.

\section{Imaging}

Ultrasound of the left knee showed effusion. Abdominal ultrasound detected splenomegaly with span of $157 \mathrm{~mm}$. Whole body bone scan by Tc99m_MDP found bony lesion in the left knee. Serial electrocardiography along hospitalization showed normal sinus rhythm with sinus tachycardia. Echocardiographic diameters were measured as transthoracic, which reported Left Ventricular (LV) enlargement with diameter of $62 \mathrm{~mm}$, mild Mitral valve Regurgitation (MR), and mild LV systolic dysfunction with Left Ventricular Ejection Fraction (LVEF) of 45\%. Transesophageal
Echocardiography (TEE) reported no vegetation, no Aortic Insufficiency (AI), trivial mitral valve regurgitation and Tricuspid valve Regurgitation (TR) and mild LV systolic dysfunction with LVEF of 45\%. Chest X-Ray (CXR), spiral Computed Tomography (CT) of the lung, carotid artery ultrasound was evaluated by B-mode, brain CT, brain Magnetic Resonance Imaging (MRI) were reported as normal. Doppler ultrasound exam of upper and lower extremity arterial and venous regions were normal. Pathological findings were not found on gastrointestinal endoscopy.

\section{Diagnosis and Treatment}

Behcet's disease was confirmed on the basis of recurrent oral and genital ulcers, pseudofolliculitis, monoarthritis, cardiovascular involvement, and no evidence of other inflammatory disease. Azathioprine $150 \mathrm{mg} / \mathrm{d}$ and prednisolone $60 \mathrm{mg} / \mathrm{d}$ were started for the patient and according to cardiac findings, captopril, Metoral, and carvedilol were begun. He is currently being followed up.

\section{DISCUSSION}

The authors hereby have reported a case of $\mathrm{BD}$ with dilated cardiomyopathy. He was presented with fever, night sweats, anorexia and weight loss, pain, and swelling in the left knee. Oral and genital aphthous ulcers, pseudofolliculitis, tachycardia, arthritis, splenomegaly, Erythrocyte Sedimentation Rate (ESR) and C - reactive protein (CRP) elevation, Left Ventricle (LV) enlargement with diameter of $62 \mathrm{~mm}$ and $\mathrm{LV}$ systolic dysfunction with LVEF of $45 \%$ were found in the evaluation. The patient fulfilled the international criteria for BD $[7,12]$ with oral and genital aphthous ulcers, pseudofolliculitis, along with arthritis and cardiovascular involvement, while an alternative diagnosis was absent.

\section{Epidemiology}

Behcet's disease is thought to be more common along the ancient Silk Road, extending from Asia to the Mediterranean [13]. The highest prevalence of BD was seen in Turkey, with 420 cases per 100000 individuals. The prevalence of BD in Japan, Korea, China, Iran, and Saudi Arabia is also high [14].

\section{Gender}

As the current case was male, BD was more common in males in the Middle East, with a male-to-female ratio of 2:1. Despite the variability of the reported gender ratios, the disease tends to run a more severe course in males [15].

\section{Age}

As in the case of this study, BD is usually seen in patients in the late third and early fourth decades of life. However, it is rarely seen in childhood years, before school age, and in pediatric patients [16].

\section{Pathophysiology}

Affected lesions of BD demonstrate microscopic evidence of inflammatory tissue infiltration with both $\mathrm{T}$ cells and neutrophils [7, 17]. Results of recent Genome-Wide Asso- 
ciation Studies (GWASs) confirm the association of BD with HLA-B51, IL-10, and IL23/17 [18].

\section{Etiology}

The etiology of BD is unknown. However, it may be triggered by a cross-reactive autoimmune response, cytokines, smoking, viral, and bacterial factors; also, a familial aggregation is well-known meaning that carriers of HLA-B51/HLA-B5 have an increased risk of developing $\mathrm{BD}[19,20]$. The case in this study reported that his father had died at middle age due to $\mathrm{BD}$ and cardiomyopathy.

\section{History and Physical findings}

History and physical findings including oral and genital ulcerations, uveitis, erythema nodosum, pseudofolliculitis rash and mono-arthritis or poly-arthritis occur in at least $50 \%$ of patients; also, CNS involvement, such as meningitis, encephalitis, and focal neurological deficits occur in as many as $25 \%$ of patients. Cardiac involvement includes any of the 3 layers of the heart involvement and coronary artery disease, and cardiac valves may develop vegetations with subsequent emboli. Vascular involvement includes migratory superficial thrombophlebitis, deep venous thrombosis in veins, arteritis and aneurysm formation, which may involve the aorta or its branches. The pathergy test is helpful but is not sensitive or specific for the diagnosis of BD [21, 22 .

\section{Treatment}

Treatment of $\mathrm{BD}$ must be appropriate to the individual patient, severity of disease, and major organ involvement. Corticosteroids are useful in controlling acute manifestations. Colchicine has also been used to prevent mucocutaneous relapse [23]. For severe mucocutaneous lesions, systemic corticosteroids, azathioprine, pentoxifylline, dapsone, interferon-alfa, colchicine, and thalidomide have demonstrat TNF- $\alpha$ blockers, cyclosporine A, interferon-alfa, cyclophosphamide, rituximab, alemtuzumab, and golimumab [24-26].

\section{ACKNOWLEDGEMENTS}

The authors would also extend their gratitude to Dr Morteza Motedayen for his special contribution to this study.

\section{CONFLICTS OF INTEREST}

None

\section{REFERENCES}

1. Alpsoy E. Behcet's disease: A comprehensive review with a focus on epidemiology, etiology and clinical features, and management of mucocutaneous lesions. J Dermatol. 2016;43(6):620-32. DOI: 10.1111/1346-8138.13381 PMID: 27075942

2. Butt SU, McNeil J. Complete heart block in a Caucasian woman with Behcet's disease: a case report. J Med Case Rep. 2016;10:102. DOI: 10.1186/s13256-016-0890-y PMID: 27095010

3. Hong SN, Park JC, Yoon NS, Lee SR, Kim KH, Hong YJ, et al. Carotid artery intima-media thickness in Behcet's disease patients without significant cardiovascular involvement. Korean J Intern Med. 2008;23(2):87-93. PMID: 18646511
4.

Sezen Y, Buyukhatipoglu H, Kucukdurmaz Z, Geyik R. Cardiovascular involvement in Behcet's disease. Clin Rheumatol. 2010;29(1):7-12. DOI: 10.1007/s10067-009-1302-0 PMID: 19830382

5. Farouk H. Behcet's disease, echocardiographers, and cardiac surgeons: together is better. Echocardiography. 2014;31(6):783-7. DOI: $10.1111 /$ echo.12524 PMID: 25041047

6. Leonardo NM, McNeil J. Behcet's Disease: Is There Geographical Variation? A Review Far from the Silk Road. Int J Rheumatol. 2015;2015:945262. DOI: 10.1155/2015/945262 PMID: $\underline{26798344}$

7. Al Izzi M, El Bur M, Arif M. A diagnosis not to be missed: Behcet's disease as a cause of dilated cardiomyopathy in a young Arab male patient. Int J Rheum Dis. 2010;13(1):97-9. DOI: 10.1111/j.1756185X.2009.01451.x PMID: 20374394

8. Cocco G, Gasparyan AY. Behcet's Disease: an Insight from a Cardiologist's Point of View. Open Cardiovasc Med J. 2010;4:63-70. DOI: 10.2174/1874192401004020063 PMID: 20360978

9. Yagmur J, Sener S, Acikgoz N, Cansel M, Ermis N, Karincaoglu Y, et al. Subclinical left ventricular dysfunction in Behcet's disease assessed by two-dimensional speckle tracking echocardiography. Eur J Echocardiogr. 2011;12(7):536-41. DOI: 10.1093/ejechocard/ jer088 PMID: 21676963

10. Demirelli S, Degirmenci H, Inci S, Arisoy A. Cardiac manifestations in Behcet's disease. Intractable Rare Dis Res. 2015;4(2):70-5. DOI: 10.5582/irdr.2015.01007 PMID: 25984424

11. Leibowitz D, Korem M, Livovsky DM, Peleg H, Chajek-Shaul $\mathrm{T}$, Hiller N. Intracardiac mass as initial cardiac manifestation of Behcet's disease: think before you cut. Echocardiography. 2014;31(8):E243-6. DOI: 10.1111/echo.12653 PMID: 24931010

12. Lee SS, Yoon HJ, Chang HK, Park KS. Fibromyalgia in Behcet's disease is associated with anxiety and depression, and not with disease activity. Clin Exp Rheumatol. 2005;23(4 Suppl 38):S15-9. PMID: 16273759

13. Marzban M, Mandegar MH, Karimi A, Abbasi K, Movahedi N, Navabi MA, et al. Cardiac and great vessel involvement in "Behcet's disease”. J Card Surg. 2008;23(6):765-8. DOI: 10.1111/j.15408191.2008.00607.x PMID: 19017008

14. Krause I, Yankevich A, Fraser A, Rosner I, Mader R, Zisman D, et al. Prevalence and clinical aspects of Behcet's disease in the north of Israel. Clin Rheumatol. 2007;26(4):555-60. DOI: 10.1007/ s10067-006-0349-4 PMID: 16897122

15. Heper G, Polat M, Yetkin E, Senen K. Cardiac findings in Behcet's patients. Int J Dermatol. 2010;49(5):574-8. DOI: 10.1111/j.13654632.2010.04424.x PMID: 20534096

16. Direskeneli H, Eksioglu-Demiralp E, Yavuz S, Ergun T, Shinnick T, Lehner $\mathrm{T}$, et al. $\mathrm{T}$ cell responses to $60 / 65 \mathrm{kDa}$ heat shock protein derived peptides in Turkish patients with Behcet's disease. J Rheumatol. 2000;27(3):708-13. PMID: 10743813

17. Ozen S, Eroglu FK. Pediatric-onset Behcet disease. Curr Opin Rheumatol. 2013;25(5):636-42. DOI: 10.1097/BOR.0b013e328363ea8b PMID: 23872902

18. Ulusan Z, Karadag AS, Tasar M, Kalender M, Darcin OT. Behcet's disease and cardiovascular involvement: our experience of asymptomatic Behcet's patients. Cardiovasc J Afr. 2014;25(2):63-6. DOI: $10.5830 /$ CVJA-2014-003 PMID: 24844550

19. Baharav E, Weinberger A. The HLA-B*5101 molecule-binding capacity to antigens used in animal models of Behcet's disease: a bioinformatics study. Isr Med Assoc J. 2012;14(7):424-8. PMID: 22953618

20. Hamzaoui K, Berraies A, Kaabachi W, Ammar J, Hamzaoui A. Pulmonary manifestations in Behcet disease: impaired natural killer cells activity. Multidiscip Respir Med. 2013;8(1):29. DOI: 10.1186/2049-6958-8-29 PMID: 23556512

21. Alpsoy E, Zouboulis CC, Ehrlich GE. Mucocutaneous lesions of Behcet's disease. Yonsei Med J. 2007;48(4):573-85. DOI: 10.3349/ymj.2007.48.4.573 PMID: 17722228

22. Fichtlscherer S, Rosenberger G, Walter DH, Breuer S, Dimmeler $S$, Zeiher AM. Elevated C-reactive protein levels and impaired endothelial vasoreactivity in patients with coronary artery disease. Circulation. 2000;102(9):1000-6. PMID: 10961964

23. Hatemi G, Silman A, Bang D, Bodaghi B, Chamberlain AM, Gul A, et al. EULAR recommendations for the management of Behcet disease. Ann Rheum Dis. 2008;67(12):1656-62. DOI: 10.1136/ ard.2007.080432 PMID: 18245110 
24. Ueda A, Takeno M, Ishigatsubo Y. Adalimumab in the management of Behcet's disease. Ther Clin Risk Manag. 2015;11:611-9. DOI: 10.2147/TCRM.S56163 PMID: 25926738

25. Vallet H, Riviere S, Sanna A, Deroux A, Moulis G, Addimanda $O$, et al. Efficacy of anti-TNF alpha in severe and/or refractory Behcet's disease: Multicenter study of 124 patients. J Autoim- mun. 2015;62:67-74. DOI: 10.1016/j.jaut.2015.06.005 PMID 26162757

26. Hatemi G, Melikoglu M, Tunc R, Korkmaz C, Turgut Ozturk B,

Mat C, et al. Apremilast for Behcet's syndrome--a phase 2, placebo-controlled study. N Engl J Med. 2015;372(16):1510-8. DOI: 10.1056/NEJMoa1408684 PMID: 25875256 